\title{
Enseñanza ¿a favor de quién?
}

Maria Graciela DI FRANCO

$\mathrm{L}$ a enseñanza es el tema de este número. Enseñanza que interpela nuestra formadel lado "de los condenados de la tierra" y nos convierte en sujetos de acción y transformación, de ruptura, de responsabilidad. En este sentido, enseñar no es transferir conocimientos, sino crear las posibilidades de su producción o construcción (Freire, 1996:24). Esta concepción exige preguntarse a favor de quién se ordena la enseñanza, obliga a tomar partido por otros/as e instalarla como espacio de poder para crear formas pedagógicas a favor de la democratización de saberes, posiciones, subjetividades.

Este modo de intervención da lugar a una enseñanza crítica.

$\mathrm{Y}$ lo es porque ofrece herramientas a las personas para construir autonomía. Diría Freire, que no es posible hablar de autonomía si no ejercemos esta capacidad de conocer, comprender e indignarnos ante un mundo cada vez más excluyente.

Mi rabia, mi justa ira, se funda en mi revuelta ante la negación del derecho de "ser más" inscrito en la naturaleza de los seres humanos. Por eso, no puedo cruzarme de brazos, en plan fatalista, ante la miseria [...] El sistema capitalista alcanza en el neoliberalismo globalizante el máximo de eficacia de su maldad intrínseca (Freire, 2001:89).

Nunca más actuales sus palabras.

Necesitamos una escuela y una enseñanza contra la ética del mercado y el pensamiento único que silencian la crítica y la lucha porque domestican nuestra educación.

El pensamiento único busca que las personas aceptemos como naturales y dadas, inevitables, las injusticias del actual orden social. También Gramsci nos ayuda pensar en este sentido: en la sociedad civil predominan determinadas ideas; predominio que Gramsci denomina hegemonía. La cual no consiste en la imposición consciente de las ideas de un grupo de personas sobre otro sino que se ejerce cuando ciertas ideas saturan profundamente la conciencia de una sociedad.

Según Therborn las ideologías someten a los sujetos porque les dicen:

- Lo que existe y lo que no (conciencia de quiénes somos, qué es el mundo, la naturaleza, el ser hombre, ser mujer, etc.).

- Lo que es bueno (correcto, justo, atractivo, agradable) y lo que no.

- Lo que es posible y lo que no (consciencia de la posibilidad y sentido del cambio) lo que normaliza los deseos y las aspiraciones (Therborn, 1987:15-16)

Y agregaríamos, -de la línea argumental de Torres Santomé- que con estas tres dimensiones se consolida el discurso de mantenimiento del orden establecido en una sociedad. En función de ellas, los intelectuales orgánicos elaborar modalidades como: a) enfatizar aspectos que refuerzas los intereses dominantes o la negación de la existencia de lo injusto (no hay pobreza, ni analfabetismo, ni hambre); b) ante la dificultad de ocultar esas injusticias, 
se disfraza la realidad ofreciendo como razón explicativa a los sujetos particulares como responsables de esa situación (son pobres porque son vagos y no quieren trabajar). c) y en muchas ocasiones defienden la imposibilidad de actuar de otra manera (siempre hubo pobres). "El miedo y la resignación serán los dos ejes en los que se moverá el discurso de justificación de lo que es posible" (Torres Santomé, 1991:19). Esta imposibilidad reduce la capacidad de resistencia, normaliza el deseo y naturaliza la mirada. Se instala un "sentido común" que contribuye a que determinadas situaciones lleguen a ser percibidas como naturales, dadas, sin posibilidad de modificación.

La enseñanza crítica se encamina a fracturar esa naturalización, ese pensamiento único porque trabaja a favor de la emancipación de las personas, la cual permite no sólo la creación de significados, sino también la capacitación para que los individuos tomen las riendas de sus propias vidas de manera autónoma y responsable. Diría Shirley Grundy (1991), es un eidos de 'liberación', entendiéndose que la libertad es un bien humano fundamental, íntimamente vinculado al acto del hablar. Este lleva implícito el principio de la libertad. La emancipación se convierte en el acto de descubrir la propia voz y ello se fortalece a partir de la construcción y comprensión de las relaciones de poder.

Esta mirada exige identificar esas relaciones de poder y esclarecer el rol de la escuela y de la docencia en la construcción del sentido común, de las naturalizaciones que nos sostiene en lugares sociales muy condicionados, reduciendo nuestras posibilidades de resistir, molestar, generar tensiones y cambios.

La historia de la educación desde que se generaliza a toda la población puede ser leída también en sus efectos como la historia de la institucionalización y de la legitimación del fracaso escolar de la clase trabajadora y de los grupos sociales desfavorecidos, pese a la existencia de un discurso explícito que insiste, una y otra vez, en la educación como única solución a la que la sociedad puede recurrir para conseguir una sociedad más igualitaria (Jurjo Torres, 1992: 33).

Esta mirada política pone en tensión el argumento de la objetividad y neutralidad del sistema educativo y de la escolarización; aquel por el cual quien trabaje duramente y sea inteligente tendrá éxito (Popkewitz, 1987). Al poder corrernos de la mirada ingenua de las teorías de consenso, las pedagogías críticas nos permiten entender la relación sociedad y educación abandonando la perspectiva ingenua de la escuela meritocrática y concibiendo a la misma inmersa en una sociedad que vive en profundo conflicto de diferencias (etnias, género, razas, clases) y reproduce dicho conflicto y la dominación concomitante. En ese territorio se construyen las resistencias.

Detectar y promover prácticas pedagógicas que contengan elementos de contestación ideológica para revertir los intereses de reproducción de las desigualdades y la dominación hegemónica implica favorecer la transformación, tanto de las relaciones educativas, como del desarrollo de una conciencia reflexiva y crítica. La enseñanza debe recuperar esta mirada para volverse crítica, interpeladora de medios, de prácticas, de instituciones, de saberes.

Las y los autores de este volumen colaborar en pensar en ese sentido. Desde unos argumentos orientados a entender al fracaso escolar y la relación con el saber; la construcción de la otredad en el fundante vínculo educativo; a la lectura crítica de medios; a las posibilidades de los saberes que circulan en la universidad y en la escuela; todos nos ayuda a generar prácticas que potencien una formación ciudadana.

Estos y otros autores y propuestas nos ayudaran a actuar esa praxis transformadora de las que nos hablaba el maestro P. Freire para seguir aprendiendo con él la necesidad de cuidar esta amenazada democracia donde sobreviven prácticas neocolonializadas que necesitamos fracturar con más fuerza que nunca.

Atrevámonos a pensar desde otra geopolítica la enseñanza y la escuela.

Despedimos y dedicamos este número al gran educador Eduardo Remedi, que desde muy temprano de nuestra vida institucional nos ayudó a pensar -tanto en la maestría en evaluación como en esta misma revista- la formación docente como construcción política e institucional. 


\section{Bibliografía}

Freire. P: (2001). Pedagogía de la indignación. Madrid: Morata.

Freire, P. (1997). Pedagogía de la autonomía. Saberes necesarios para la práctica educativa. México: Siglo XXI.

Gramsci, A. (1986). Literatura y vida nacional. México: Juan Pablos Editor.

Grundy, S. (1991). Producto o praxis del curriculum. Madrid: Morata.

Popkewitz, T. (1994). Sociología política de las reformas educativas. Madrid: Morata.

Torres Santomé, J. (1992) El curriculum oculto. Madrid: Morata

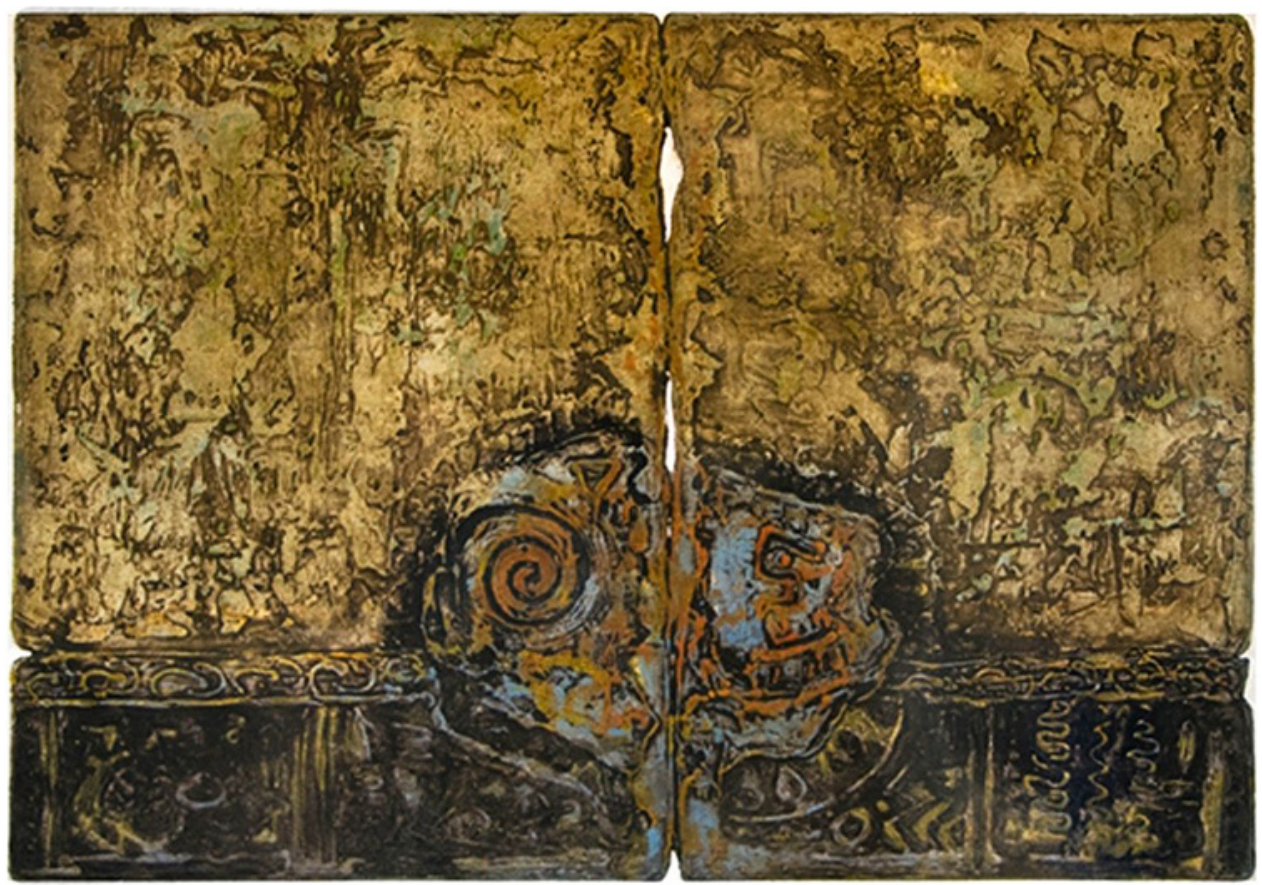

“El Muro", collagraph. Marta Arangoa 